\title{
An Evaluation of the Opinions of Primary School Trainee Teachers towards Teaching Practice Course
}

\author{
Barış Kalender \\ Gaziantep University/ Faculty of Education
}

\begin{abstract}
In this study, it is aimed to determine the problems faced by primary school trainee teacher during the teaching practice process. The study was conducted within the scope of the case study. The study was carried out with six volunteer students from 133 4th primary school teacher who took teaching practice lessons. Focus group interviews were conducted with six primary school trainee teachers. Transcripts of the interviews were prepared. The data were analyzed by content analysis. Three different categories and 18 codes were reached from the interviews. The categories; evaluation of mentor teacher, evaluation of course instructor and evaluation of school administration. As a result of the study, it was found that some of the mentor teachers had positive and some of them had negative practices. It has been concluded that there are some tasks that are expected from the instructor but not fulfilled adequately. The school administration did not provide sufficient guidance and support to trainee teachers. According to the results obtained from the study, it is thought that it would be beneficial for the mentor teachers and course instructors to undergo a training on teaching practice. It is thought that a communication channel should be established between the administration school and the faculty of education.
\end{abstract}

Keywords: teaching practice; primary school teacher; teacher candidate; school; education 